\title{
Primary health care services utilization and satisfaction among the elderly in Asir region, Saudi Arabia
}

\author{
A.A. Mahfouz, ${ }^{1}$ A.I. Al-Sharif, ${ }^{2}$ M.N. El-Gamal' ${ }^{2}$ and A.H. Kisha ${ }^{2}$ \\ مدى الانتفاع بخدمات الرعاية الصحية الأولية ودرجة الوضى عنها بين المسنيّين في منطقة عسير

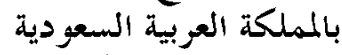

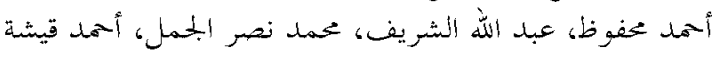

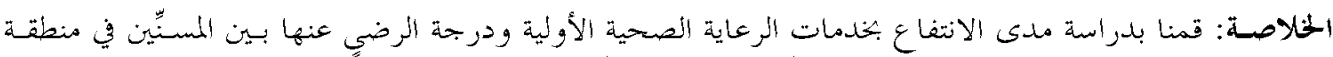

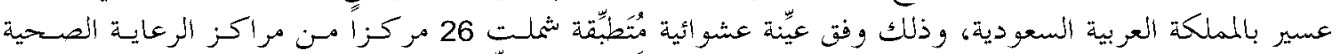

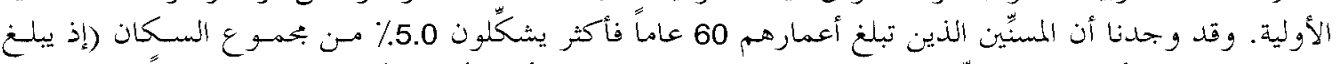

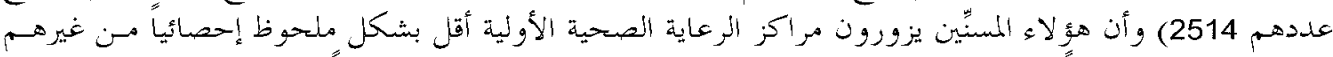

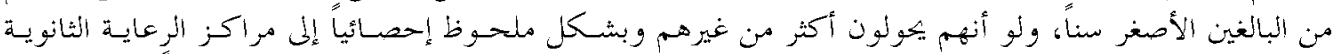

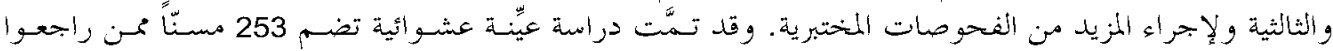

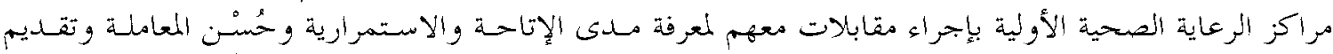

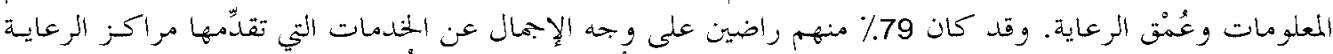

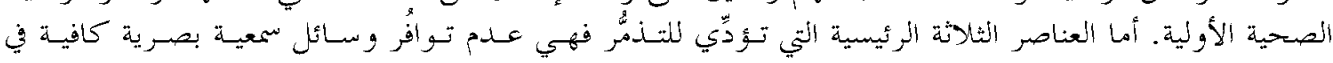

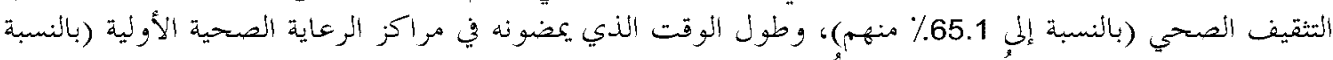

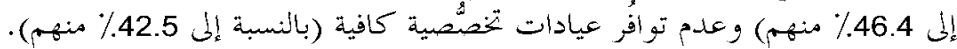

ABSTRACT Use of primary health care (PHC) services and satisfaction among elderly people $(60+$ years) in Asir was studied in $26 \mathrm{PHC}$ centres. They visited PHC centres significantly less often than younger adults but they were referred significantly more often to secondary and tertiary care and for more laboratory tests. A random sample of 253 elderly people attending the centres was interviewed about accessibility, continuity, humaneness, informativeness and thoroughness of care. Overall, $79.0 \%$ were satisfied with the services provided. The leading 3 items of dissatisfaction were: not enough audiovisual means for health education $(65.1 \%)$, long time spent in the centre (46.4\%), and not enough specialty clinics $(42.5 \%)$.

\begin{abstract}
Utilisation des services de soins de santé primaires et satisfaction des personnes âgées à l'égard de ces services dans la région d'Asir (Arabie saoudite)

RESUME L'utilisation des services de soins de santé primaires (SSP) par les personnes âgées et leur satisfaction à l'égard de ces services dans la région d'Asir (Arabie saoudite) ont été étudiées dans un échantillon aléatoire stratifié de 26 centres SSP. Elles se rendaient dans les centres SSP significativement moins souvent que les adultes plus jeunes mais elles étaient orientées significativement plus souvent vers les soins secondaires et tertiaires et pour des examens de laboratoire supplémentaires. On a interrogé un échantillon aléatoire de 253 personnes âgées fréquentant ces centres au sujet de l'accessibilité, de la continuité, de l'humanité, de l'informativité et de l'exhaustivité des soins. Globalement, $79,0 \%$ des personnes étaient satisfaites des services SSP fournis. Les trois principaux éléments de mécontentement étaient les suivants : l'insuffisance de moyens audiovisuels pour l'éducation sanitaire $(65,1 \%)$, la longueur du temps passé au centre (46,4\%), et l'insuffisance de consultations spécialisées (42,5\%).
\end{abstract}

${ }^{1}$ Department of Family and Community Medicine, College of Medicine, King Khalid University, Abha, Saudi Arabia.

${ }^{2}$ Asir General Directorate of Health Affairs, Asir, Saudi Arabia.

Received: 08/04/02; accepted: 29/09/03

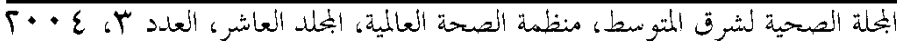




\section{Introduction}

In recent decades, there has been a sharp increase worldwide in the number of people surviving to older ages. This demographic change is proceeding more rapidly in developing countries [1]. However, the rapid pace of socioeconomic growth and improved provision of health and other social services in Saudi Arabia will in due course lead to a similar increase in the elderly population of our country. Elderly individuals are an integral part of society and are entitled to their fair share of the health and social services that are provided. Furthermore, because of their frailty and vulnerability, old people have special needs for care.

Various methods have been used to assess the adequacy of patients' utilization of health services in general and of primary health care services in particular. Patient satisfaction is considered an important indicator of the efficient utilization of health services, as it assesses an individual's attitude to health services received and the extent to which these services meet the person's requirements and needs [2-4]. A review of patient satisfaction studies show that the characteristics of health care delivery that most influence patient satisfaction are: accessibility, continuity, humaneness, informativeness and thoroughness of care [5-9].

Asir region (population around 1200000 ) is located in the southwest of Saudi Arabia, covering an area of more than $80000 \mathrm{~km}^{2}$. The region extends from the high mountains of Sarawat (at an altitude of $3200 \mathrm{~m}$ above sea level) to the Red Sea, and lies a few kilometres from the northern border of neighbouring Yemen [10]. Primary health care in Asir region is provided through a widespread network of 208 primary health care (PHC) centres. Each PHC centre has a well-defined catchment area and population [11]. Secondary and tertiary care services in the region are provided through a network of 15 hospitals across the region.

The aim of the present work was to study the pattern of utilization of primary health care services and satisfaction among elderly people in Asir region.

\section{Methods}

Twenty-six PHC centres (12.5\%) were chosen using a proportional allocation multistage stratified random sampling technique. The sample was selected taking into consideration rural-urban differences and altitude. Family health records of the chosen centres were reviewed to identify elderly adults (aged 60 years and above) and non-elderly adults (aged 15 to less than 60 years). The pattern of utilization of the available PHC services among both groups was studied: number of visits per year, number of referrals to secondary and tertiary care and number of laboratory analyses carried out (blood, stool and urine tests).

A systematic random sample of $10 \%$ of elderly people in the chosen centres was selected. Through a house-to-house survey, well-trained Arabic-speaking community health workers interviewed them about their satisfaction with the PHC services provided. A structured questionnaire for measuring satisfaction was used. The instrument was grouped into 5 categories: accessibility, continuity, humaneness, thoroughness and informativeness [12].

Data were analysed using SPSS PC+ software package. Chi-squared and Student $t$ tests were used as tests of significance at the $5 \%$ level of significance $[13,14]$.

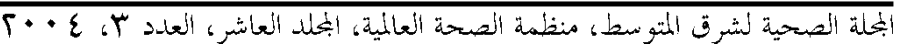




\section{Results}

The 26 PHC centres selected included 6 urban and 20 rural centres. They provide services to 7498 Saudi families, including 50392 Saudi Arabians residing in the catchment areas. The profile of the selected centres was similar to Asir region as a whole; $48 \%$ of the chosen PHC centres had laboratories, $20 \%$ had X-ray facilities and $48 \%$ had dental services. The mean \pm SD number of physicians was $1.95 \pm 0.24$ and the mean number of nurses was $3.71 \pm$ 0.42 .

Review of family health records at the centres identified 2514 Saudi Arabian adults aged 60 years and above (5.0\%). The majority of the elderly people were female $(55.3 \%)$, married $(76.0 \%)$ and illiterate (93.0\%). The mean \pm SD age was $67.5 \pm$ 17.3 years with a median of 66 years.

\section{Utilization of PHC services}

Table 1 shows the pattern of utilization of PHC services among the 2514 elderly and 24692 non-elderly adults. On average, the elderly people visited the PHC centres sig- nificantly fewer times per year than the younger adult age group. On the other hand, the elderly people were significantly more often referred to secondary or tertiary care and used laboratory facilities more often than the younger adult age group.

\section{Satisfaction survey}

A total of 253 elderly people (aged 60+ years) were interviewed about their satisfaction with the PHC services provided. A majority $(200,79.0 \%)$ of the interviewees were satisfied with the services and reported that they preferred always to use the health services provided by the centre.

The lowest items of satisfaction of 'accessibility' of services were those related to the long waiting time spent in the centre and availability of the telephone at the centre (Table 2). The majority was satisfied by various elements of 'continuity' of services.

Questions about the 'humaneness' of services (Table 2) showed that 8 out of 10 elderly people felt that the least welcoming health team members were dentists and laboratory workers. Regarding 'informa-

Table 1 Pattern of utilization of primary health care services among elderly (60+ years) and younger adults (15-60 years) in Asir region, Saudi Arabia

\begin{tabular}{lllll}
\hline Pattern of utilization & \multicolumn{2}{c}{ Mean \pm SD } & Difference & 95\% Cl \\
& $\begin{array}{l}\text { Elderly } \\
(\boldsymbol{n}=\mathbf{2 5 1 4})\end{array}$ & $\begin{array}{c}\text { Adults } \\
(\boldsymbol{n}=\mathbf{2 4} \text { 692) }\end{array}$ & & \\
\hline $\begin{array}{l}\text { Average number of visits } \\
\quad \text { per person per year }\end{array}$ & $3.98 \pm 0.57$ & $6.01 \pm 0.75$ & 2.03 & $1.66-2.41^{*}$ \\
Referrals per 100 visits & $6.49 \pm 0.93$ & $3.19 \pm 0.47$ & 3.30 & $2.89-3.71^{*}$ \\
Blood analysis per 100 visits & $5.18 \pm 0.74$ & $4.17 \pm 0.52$ & 1.01 & $0.65-1.36^{*}$ \\
Stool analysis per 100 visits & $1.94 \pm 0.26$ & $1.44 \pm 0.25$ & 0.50 & $0.35-0.64^{*}$ \\
Urine analysis per 100 visits & $9.60 \pm 1.35$ & $4.44 \pm 0.55$ & 5.16 & $4.58-5.73^{*}$ \\
\hline${ }^{*} P<0.05$. & & & & \\
$\mathrm{n}=$ total number of people studied. & & & \\
$S D=$ standard deviation; $C l=$ confidence interval. & & & &
\end{tabular}

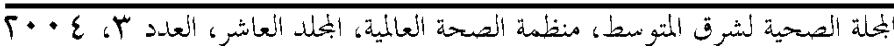


Table 2 Satisfaction of elderly health care recipients with 5 aspects of primary health care (PHC) services in Asir region, Saudi Arabia

\begin{tabular}{|c|c|}
\hline Aspects of PHC services & $\begin{array}{l}\text { \% satisfied } \\
(n=253)\end{array}$ \\
\hline \multicolumn{2}{|l|}{ Accessibility } \\
\hline Duty hours are sufficient & 90.1 \\
\hline $\begin{array}{l}\text { Transportation to the centre is } \\
\text { suitable }\end{array}$ & 84.9 \\
\hline Distance to the centre is not too far & 82.9 \\
\hline $\begin{array}{l}\text { Waiting areas in the centre are } \\
\text { sufficient }\end{array}$ & 81.7 \\
\hline $\begin{array}{l}\text { Guide marks are available in and to } \\
\text { the centre }\end{array}$ & 79.8 \\
\hline $\begin{array}{l}\text { Parking areas at the centre are } \\
\text { sufficient }\end{array}$ & 77.4 \\
\hline $\begin{array}{l}\text { Use of telephone in the centre is } \\
\text { possible }\end{array}$ & 62.5 \\
\hline $\begin{array}{l}\text { Time spent in the centre is } \\
\text { acceptable }\end{array}$ & 53.6 \\
\hline \multicolumn{2}{|l|}{ Continuity } \\
\hline $\begin{array}{l}\text { Referral to hospital if needed is } \\
\text { possible and easy }\end{array}$ & 96.0 \\
\hline Follow-up is by the same physician & 92.1 \\
\hline $\begin{array}{l}\text { Defaulters are usually reminded by } \\
\text { centre }\end{array}$ & 87.3 \\
\hline \multicolumn{2}{|l|}{ Humaneness } \\
\hline Record workers are welcoming & 96.8 \\
\hline Doctors are welcoming & 96.4 \\
\hline Pharmacy workers are welcoming & 95.2 \\
\hline Nurses are welcoming & 94.4 \\
\hline $\begin{array}{l}\text { Centre personnel care about any } \\
\text { complaint }\end{array}$ & 91.7 \\
\hline Laboratory workers are welcoming & 87.2 \\
\hline Dentists are welcoming & 81.0 \\
\hline
\end{tabular}

tiveness' of services, only $34.9 \%$ were satisfied by the available audiovisual means of health education in the centre. The study showed that only $57.5 \%$ were satisfied by the availability of specialty clinics in the centre. A high proportion was satisfied with the thoroughness of clinical examinations.

Thus the leading 3 items of dissatisfaction were: not enough audiovisual means

\begin{tabular}{lc}
\hline Aspects of PHC services & $\begin{array}{c}\text { \% satisfied } \\
\text { ( } \boldsymbol{n} \text { = 253) }\end{array}$ \\
\hline $\begin{array}{l}\text { Informativeness } \\
\text { Physicians reply to questions }\end{array}$ & 97.6 \\
$\begin{array}{l}\text { Pharmacists explain how to use } \\
\text { medicine }\end{array}$ & 97.0 \\
$\begin{array}{l}\text { Health education at centre is } \\
\text { sufficient }\end{array}$ & 75.9 \\
$\begin{array}{l}\text { Audiovisual systems in the centre } \\
\text { are sufficient }\end{array}$ & 34.9 \\
$\begin{array}{l}\text { Thoroughness } \\
\text { Vital signs are always taken } \\
\text { Clinical examination is thorough }\end{array}$ & 96.4 \\
$\begin{array}{l}\text { Drug availability at the centre is } \\
\text { sufficient }\end{array}$ & 84.0 \\
$\begin{array}{l}\text { Health team at the centre is } \\
\text { sufficient } \\
\text { Specialty clinics at the centre are } \\
\text { sufficient }\end{array}$ & 67.2 \\
\hline $\mathrm{n}=$ total number of interviewees. & 57.5 \\
\hline
\end{tabular}

for health education $(65.1 \%)$, long waiting times in the centre $(46.4 \%)$ and not enough specialty clinics $(42.5 \%)$. No statistical significant differences $(P>0.05)$ in the prevalence of various elements of satisfaction were found by sex, age group and level of education of the elderly people interviewed.

\section{Discussion}

Similar to other reports from Saudi Arabia $[15,16]$, the present study showed that the proportion of those aged 60 years and above amounted to 5\%. The United Nations estimates that the proportion of people over 65 years of age living in the countries of the Eastern Mediterranean Region of the World Health Organization is approximately 3.5\%, and is expected to approach $3.6 \%$ by 2005 [1]. 
The present study showed that elderly people tend to visit the PHC centre less often than younger adults. Similar results were reported in other developing [17] and developed countries $[18,19]$. On the other hand, once the elderly attended the PHC centre they used the diagnostic facilities more often and were referred more often than the younger age group. The morbidity pattern of elderly patients attending PHC centres, especially the preponderance of chronic diseases [15], may explain the excess. Demographic changes in Saudi Arabia will lead to an increasingly larger share of health services being allocated to the elderly population. Health services for the elderly may benefit from an outreach approach that makes both clients and providers aware of the availability and usefulness of a range of programmes to address various problems.

In the present study, satisfaction with health care was the criterion of quality of service; overall $79.0 \%$ of the interviewed elderly persons expressed their satisfaction with the PHC services provided. Similar studies in Saudi Arabia showed satisfaction levels around $60 \%[12,20-22]$. On the other hand, studies in developed countries have found similar high levels of satisfaction, around $78 \%[23,24]$.

The respondents were satisfied with most of the items assessing accessibility of care except the one related to waiting time at the PHC centre. Long waiting time has also been reported as an item of dissatisfaction by several researchers $[12,20]$. This may be due to understaffing and/or lack of facilities.

With regard to 'humaneness' of care, complaints about the behaviour of some primary health care staff centred around the fact that patients felt that there was no sympathy for them. Laboratory workers and dentists ranked lower than other health workers. Only half of PHC centres in Asir region have their own dentists and laboratories. The rest refer patients to the nearest PHC centre with that service. PHC workers may be tired or frustrated by overcrowded schedules or uneven workload. This could be corrected by better workload distribution or in-service training of the PHC team.

Regarding the 'informativeness' of care, almost all interviewees were satisfied with the information provided by physicians and pharmacists. On the other hand, half of the interviewees were dissatisfied with the available audiovisual systems. One out of every 4 elderly people was dissatisfied with the health education given by the PHC centres. Ongoing continuing medical education programmes for the entire health team should be tailored to sensitize the team to their responsibilities in health education [25].

An increase in the number of elderly people has major implications for society, affecting such areas as health and social services and public spending. The relatively higher incidence of chronic diseases and reduced mobility among the elderly requires greater health expenditure for these age groups. The World Health Organization Regional Office for the Eastern Mediterranean has drawn the attention of its member states to the increasing life expectancy in the Region's populations, and to the need to provide appropriate social and health care services to emerging elderly populations within the context of comprehensive national policies [1].

Given that the elderly population in Saudi Arabia will continue to grow in absolute and relative terms over the coming decades, health care policy-makers will need a better understanding of what contributes to that population's satisfaction and wellbeing. With continued research on the ef-

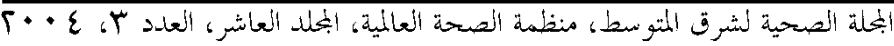


fects of community-based health care interventions on a variety of health outcomes, those setting policy will be better able to determine where funds should be allocated to promote both efficiency and client well-being.

It is recommended to improve the integration and coordination of health and wel- fare programmes and services to address effectively the various needs of older people and to improve primary health care systems to protect and promote healthy lifestyles, and to tackle the chronic health problems among an ageing population.

\section{References}

1. Hafez G, Bagchi K, Mahaini R. Caring for the elderly: a report on the status of care for the elderly in the Eastern Mediterranean Region. Eastern Mediterranean health journal, 2000, 6(4):636-43.

2. DiTomasso RA, Willard M. The development of a patient satisfaction questionnaire in the ambulatory setting. Family medicine, 1991, 23:127-31.

3. Roghmann KJ, Hengst A, Zastowny TR. Satisfaction with medical care: its measurement and relation to utilization. Medical care, 1979, 17:461-77.

4. Zastowny TR, Roghmann KJ, Hengst A. Satisfaction with medical care: replications and theoretic reevaluation. Medical care, 1983, 21:294-322.

5. Pascoe GC, Attkisson CC. The evaluation ranking scale: a new methodology for assessing satisfaction. Evaluation and program planning, 1983, 6:335-47.

6. Donabedian A. Evaluating the quality of medical care. Milbank Memorial Fund quarterly, 1966, 44:166-203.

7. El-Guebaly $\mathrm{N}$ et al. On evaluating patient satisfaction: methodological issues. Canadian journal of psychiatry, 1983, 8:249.

8. Feletti G, Firman D, Sanson-Fisher R. Patient satisfaction with primary-care consultations. Journal of behavioral medicine, 1986, 9:389-99.
9. Linder-Pelz S, Streuning EL. The multidimensionality of patient satisfaction with a clinic visit. Journal of community health, 1985, 10:42-54.

10. Mauger T. Undiscovered Asir. London, Stacy International, 1993.

11. Al-Mazrou Y, Al-Shehri S, Rao M. Principles and practice of primary health care. Riyadh, Saudi Arabia, Al-Helal Press, 1990.

12. Mansour AA, Al-Osimy MH. A study of satisfaction among primary health care patients in Saudi Arabia. Journal of community health, 1993, 18:163-73.

13. Rimm A. Basic biostatistics in medicine and epidemiology. Norwalk, Connecticut, Appleton Century Crofts, 1980.

14. Norusis M J. SPSS/PC+4.0 for the IBM $P C / X T / A T$ and PS2. Installation Guide and Manual. SPSS Inc., Chicago, Illinois, 1990.

15. Al-Shammari SA. Causes of ill health among elderly patients seen at a primary care clinic at King Khalid University Hospital, Saudi Arabia. Saudi medical journal, 1994, 15:358-63.

16. Al-Shammari SA et al. A study of health care needs of Saudi elderly. Saudi Arabia, King Abdulaziz City of Science and Technology, 1992. 
17. Bester FC, Weich DJ, Albertyn EW. Socio-economic circumstances and functional abilities of elderly black persons in the Orange Free State. South African medical journal, 1992, 82:110-3.

18. Richardson V. Service use among African American elderly people. Social work, 1992, 37:47-54.

19. Locker $D$ et al. Utilization of dental services by older adults in four Ontario communities. Journal of the Canadian Dental Association, 1991, 57:879-86.

20. El Sabrawy AM, Mahamoud ME. A study of patient satisfaction with primary health care services in Saudi Arabia. Journal of community health, 1993, 18:49-54.

21. Al-Doghaither A, Saeed A. Consumers' satisfaction with primary health services in the city of Jeddah, Saudi Arabia. Saudi medical journal, 2000, 21(5):447-54.

22. Saeed A et al. Satisfaction and correlates of patients' satisfaction with physi- cians' services in primary health care centres. Saudi medical journal, 2001, 22(3):262-7.

23. Lebow J. Similarities and differences between mental health and health care valuation studies assessing consumer satisfaction. Evaluation and program planning journal, 1983, 6:237-45.

24. Chetwynd J. Satisfaction and dissatisfaction with public and private hospitals. New Zealand medical journal, 1988, 101:563-9.

25. Ministry of Haalth, Saudi Arabia/ World Health Organization Regional Office for the Eastern Mediterranean. Quality assurance in primary health care manual. The Scientific Committee of Quality Assurance in Primary Health Care. Riyadh, Ministry of Health, General Directorate of Health Centres, 1994.

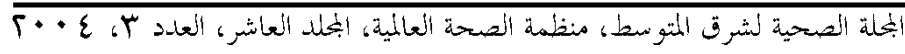

